\section{REVISTA BRASILEIRA DE QUALIDADE DE VIDA}

\title{
A mobilidade social e as práticas de lazer
}

\section{The social mobility and the leisure practices}

\author{
José Roberto Herrera Cantorani \\ Faculdades Integradas de Itararé - FAFIT - São Paulo - Brasil \\ Grupo de Estudo e Pesquisa em Políticas Públicas e Lazer da FEF-UNICAMP - Campinas - Brasil \\ cantorani@cev.org.br
}

\begin{abstract}
Resumo
O presente estudo trata da relação entre a mobilidade social e a adoção de formas de lazer. Sobretudo, toma como base as condições de vida a que as crianças se expõem na atual sociedade e busca a relação com as formas de lazer utilizadas para a sua distração e/ou satisfação. A base deste estudo está na reflexão desses problemas frente ao processo de mobilidade social, mas, em conjunto, também no processo de mobilidade cultural. Para o alcance deste objetivo é analisada a possível ligação entre a mobilidade social e os problemas do sedentarismo, e de seus derivativos, assim como, a ligação da qualidade de vida com diferentes culturas de lazer.
\end{abstract}

Palavras-chave: mobilidade social, lazer, acesso.

\begin{abstract}
The present study boards the relation between social mobility and the leisure kinds. Especially basis the lifestyles that children expose in the contemporary society and investigates the relation with the leisure kinds used to its distraction/satisfaction. The base of this study is in the reflection of these problems confronted to the process of social mobility, but, jointly, also in the process of cultural mobility. For that, it's analyzed the possible connection between social mobility and the problems of a sedentary lifestyle, as well as the connection between quality of and with different leisure cultures.
\end{abstract}

Keywords: social mobility, leisure, access.

\section{Introduçãa}

A opção pela exploração arrolada abaixo se deve à inquietações a respeito das práticas de lazer entre as as crianças na atualidade, as quais venho buscando estruturar teoricamente. $\mathrm{O}$ objeto dessas inquietações, de forma expandida, está ligado às transformações culturais que (re) significam a apropriação de formas de lazer e de satisfação no lazer, especialmente, em crianças.

Valter Bracht, em Educação Física Escolar e Lazer (2003, p. 148), justificando a sua escolha de trabalhar o lazer no conceito de cultura, faz uso do pensamento de Forquin (1993) para enfatizar a afirmação de ser a cultura o conteúdo substancial da educação, a sua fonte e justificação. Estaria a cargo da educação, por assim dizer, a responsabilidade de transmitir a experiência humana, compreendida como cultura. Não obstante, Bracht também deixa claro, desde o início, que "a noção de cultura é fundamental para a Educação Física e o lazer" (2003, p. 148). E, em relação a este último, profere: "por nós entendido como um traço específico da nossa cultura" (2003, p. 148). 
O presente estudo preocupa-se, portanto, com o modo de vida das crianças nas atuais sociedades, e, com a relação entre este modo de vida e a cultura de lazer. Para o seu desenvolvimento é abordada - posta em estudo, em justaposição - a mobilidade social, a qual compreende a passagem de um indivíduo, ou de um grupo, de uma posição social para outra, dentro de uma multiplicidade de grupos e de estratos sociais; e também a mobilidade cultural, que, por sua vez, compreende um deslocamento similar de significados, normas, valores e vínculos.

A mobilidade social, quando da perspectiva vertical ascendente, é tida como sinônimo de melhora na qualidade de vida. Sob muitos aspectos essa relação é incontestável, pois, junto com esta mobilidade tem-se o aumento do poder de aquisição, maior acesso a bens e serviços, à tecnologia, ao conforto, melhores condições de moradia e de alimentação. Contudo, sob outros aspectos, esse mesmo contexto pode significar não apenas fatores positivos, mas também problemas no que diz respeito à saúde, e, portanto, à qualidade de vida. Frente a aspectos físico-culturais de lazer, ou, em outras palavras, de existência ativa e cultural, é possível enxergar alguns problemas.

Tendo como base a mobilidade social intergeracional - sempre em observância ao princípio vertical ascendente - e, com isso, elegendo como objeto de observação as diferenças entre o estilo de vida das crianças de hoje e o estilo de vida de seus pais - quando na idade dessas crianças -, o sedentarismo, provavelmente, vai pesar negativamente - nesta análise - para o lado das crianças de hoje.

Certamente que os resultados vão variar em função do nível social de origem e o de destino eleitos como fonte de observação. O entendimento, contudo, é de que a grande mudança - alteração em relação ao estilo de vida das crianças em um contexto de mobilidade cultural - é verificada entre as camadas sociais em que as crianças estudam em escolas públicas e as camadas em que as crianças estudam em escolas particulares. Dessa forma, a delimitação do objeto de estudo se dá em torno desses dois estratos.

\section{Lazer e qualidade de vida}

A presente pesquisa tem o seu desenvolvimento sustentado no interesse pelo estudo do significado do lazer, ou da cultura do lazer, para a "qualidade de vida". A qualidade de vida, em seus múltiplos fatores - componentes e influentes - tem despertado o interesse de diversos setores do meio acadêmico-científico, sobretudo nas ciências que se ocupam dos aspectos sociais e físicos.

A qualidade de vida se tornou uma preocupação mundial. E essa preocupação resultou na dinamização de estudos e, consequentemente, na formulação de conceitos. Um exemplo dessa preocupação com a conceituação da qualidade de vida e de sua avaliação vem da própria Organização Mundial da Saúde (OMS). A divisão de Saúde Mental da OMS tem um grupo especializado na qualidade de vida, o World Health Organization Quality of Life (WHOQOL Group).

O WHOQOL Group, assim como outras entidades e organizações, leva em consideração os diferentes aspectos componentes de um amplo conceito de qualidade de vida: domínio físico, domínio psicológico, nível de independência, relações sociais, ambiente, aspectos espirituais, e as diferentes facetas que se encontram dentro de cada um desses aspectos. Fatores como atividade física e lazer encontram-se como componente desta avaliação, seja como um aspecto ou como uma faceta de um desses aspectos. O problema, contudo, é que a abordagem em relação a essas atividades é sucinta e pouco sistematizada.

A atividade física regular e de lazer, apesar de ser apontada como um dos fatores para a qualidade de vida, não vem sendo estudada de uma forma contextualizada, de uma forma que a aborde em sua relação direta com a sociedade e com os problemas enfrentados por esta. Não dá para se pensar a qualidade de vida, tampouco as atividades de lazer e as mudanças no estilo de vida das sociedades, de forma desconexa, e estudá-las de forma compartimentalizada. Esse estudo tem que superar a reificação de conceitos existente no estudo desta temática, sobretudo no que diz respeito à idéia de exterioridade entre indivíduos e sociedade, como se a sociogênese não atuasse na psicogênese e esta na primeira. 
O que se verifica, por tanto, é a carência de uma atenção mais sistematizada em relação a este contexto, principalmente em relação à vida sedentária que um número bastante grande de crianças vem sendo submetido. Não é o bastante pensar a qualidade de vida como algo inerte. Alguns aspectos da qualidade de vida, entre eles o lazer e a atividade física, estão passando por mudanças que não podem ser ignoradas, e o alvo temerário dessas mudanças são as crianças.

Os fatos mostram que os adultos, mesmo vivendo uma vida ativa fisicamente durante a infância e adolescência, enfrentam diversos problemas de saúde, resultantes de um dia-a-dia agitado, estressante e sedentário. Esses mesmos fatos provocam o pensamento interrogativo a respeito da fase adulta das crianças de hoje - com uma vida pautada em conforto e pouca atividade física.

Talvez o problema esteja na noção do que venha a ser "qualidade de vida". A qualidade de vida é uma noção eminentemente humana e, essencialmente, está ligada ao grau de satisfação encontrado ao longo de sua vida social. E, conforme descreve Minayo et al. (2000, p. 8), "pressupõe a capacidade de efetuar uma síntese cultural de todos os elementos que determinada sociedade considera seu padrão de conforto e bem-estar".

Cabe, neste ínterim, a análise do que traz satisfação às crianças hoje. E cabe, sobremaneira, a análise e reflexão sobre os elementos que se traduzem em fonte de satisfação para essas crianças e se esses elementos são, em verdade, geradores de qualidade de vida.

Os estudos de Minayo et al. (2000) abordam também a relatividade desta noção. O padrão de qualidade de vida, que em última instância remete ao plano individual, tem pelo menos três fóruns de referência.

O primeiro é histórico. Ou seja, em determinado tempo de seu desenvolvimento econômico, social e tecnológico, uma sociedade específica tem um parâmetro de qualidade de vida diferente da mesma sociedade em outra etapa histórica. O segundo é cultural. Certamente, valores e necessidades são construídos e hierarquizados diferentemente pelos povos, revelando suas tradições. $\mathrm{O}$ terceiro aspecto se refere às estratificações ou classes sociais. Os estudiosos que analisam as sociedades em que as desigualdades e heterogeneidades são muito fortes mostram que os padrões e as concepções de bem-estar são também estratificados: a idéia de qualidade de vida está relacionada ao bem-estar das camadas superiores e à passagem de um limiar a outro (MINAYO et al., 2000, p. 9).

Apesar do relativismo cultural, os autores do estudo citado acima relatam o fato de que um modelo hegemônico está a um passo de adquirir significado planetário. De acordo com os autores, trata-se daquele "preconizado pelo mundo ocidental, urbanizado, rico, polarizado por um certo número de valores" (MINAYO et al., 2000, p. 9), e que poderiam ser assim resumidos: "conforto, prazer, boa mesa, moda, utilidades domésticas, viagens, carro, televisão, telefone, computador, uso de tecnologias que diminuem o trabalho manual, consumo de arte e cultura, entre outras comodidades e riquezas" (MINAYO et al., 2000, p. 9).

Com base nas argumentações referenciadas acima firma-se a noção de que a qualidade de vida, independentemente de qual fórum se estabelece o debate, está ligada à satisfação de necessidades, à aquisição de comodidades e de bem-estar e à noção de que a passagem às camadas superiores predispõe essa condição. A qualidade de vida, conceitualmente, está ligada à mobilidade social ascendente.

É fato que a satisfação das necessidades tem um papel bastante significativo neste processo, é em busca desta satisfação que a humanidade se move, foi esse movimento que permitiu à humanidade chegar ao grau de desenvolvimento a que chegou.

Estudos e dados permitem tal entendimento. Conforme Berger e Luckmann (1976, p. 70), o homem, ao contrário dos outros mamíferos, não possui um ambiente específico da espécie, um ambiente firmemente estruturado por sua própria organização instintiva e no qual se adapte sem ter que transformá-lo. Assim, "a inerente instabilidade do organismo humano obriga o homem a fornecer a si mesmo um ambiente estável para sua conduta" (BERGER; LUCKMANN, 1976, p. 77). É em função dessa necessidade que o homem encontra-se em constante inquietação, buscando ao longo de sua história, mudar, sofisticar, civilizar o meio que o rodeia. 
Contudo, merece atenção o grau de insatisfação que atinge a humanidade e, principalmente, o nível de transformação que essa insatisfação impôs à vida em sociedade. Nesse sentido, há de se lembrar o termo "sociedade insatisfeita" que, como observado por Agnes Heller (1998), foi cunhado para destacar um traço conspícuo da identidade ocidental. De acordo com a autora, "a idéia de 'sociedade insatisfeita' busca captar a especificidade de nossa época mundial da perspectiva das necessidades ou, mais particularmente, da criação, percepção, distribuição e satisfação das necessidades" (HELLER, 1998, p. 29).

As observações feitas pela autora sugerem que a forma moderna de criação, percepção e distribuição de necessidades reforça a insatisfação, independente - e este é um dado que particularmente merece destaque - de alguma necessidade concreta ser ou não de fato satisfeita.

A necessidade e a insatisfação, de acordo com essas formulações, foram motivos para o homem, ao longo de sua história, produzir profundas transformações na sociedade e no meio que o rodeia. O modo de vida contemporâneo, em conseqüência, atinge padrões de sofisticação e de civilização extremos. Nesse sentido, o contato do homem com muito daquilo que por muito tempo foi natural, hoje é um passado que parece muito distante, sobretudo o contato com a natureza e com um ambiente mais tranqüilo, mais sereno.

É com amparo neste contexto que questionamentos são feitos em relação as condições reais e universais de manutenção de um padrão de qualidade de vida, que para Minayo et al. (2000, p.9), "fundado no consumismo e na exploração da natureza que, pelo seu elevado grau predatório, desdenha a situação das gerações futuras, desconhece a cumplicidade de toda a biosfera e não é replicável".

Com amparo neste contexto ergue-se a indagação sobre os elementos culturais em que se apóiam as crianças e adolescentes na sociedade hodierna, sobre os elementos culturais que perfazem o estilo de vida das crianças e dos adolescentes e sobre a relação desses elementos com a qualidade de vida.

\section{Qualidade de vida, lazer e saúde}

No campo da saúde está a chave para a discussão que se propõe este estudo. Em verdade, em grande parte dos estudos sobre este tema o termo de referência não é qualidade de vida, mas condições de vida. Esse termo propicia, em seu campo semântico, um entendimento mais aproximado do contexto em estudo.

Se em classes mais baixas a preocupação, em relação à saúde, é com o acesso a um ambiente físico e social mais saudável, e também o acesso à serviços de saúde, isso caracterizaria, por conseguinte, que nas classes sociais mais elevadas esses problemas estariam bastante minimizados, ou até mesmo resolvidos.

Contudo, é preciso não esquecer que o conceito de saúde, antes de qualquer ampliação ao contexto social, está relacionado - em sua base - à ausência de doenças. Também é preciso potencializar a ciência de que as conseqüências negativas do excesso de peso e da inatividade física é uma realidade com resultados severos, como vêm sendo demonstrada incansavelmente pelas referências que vêm da área da saúde. Dessas referências tem-se que a obesidade é fator de risco para hipertensão arterial, hipercolesterolemia, diabetes mellitus, doenças cardiovasculares e algumas formas de câncer. E que a inatividade física é um estado que predispõe a obesidade, e também, por si só, a muitas dessas doenças.

Assim, considerando que estilos de vida sustentados por excesso de conforto, acesso à tecnologia e diversos níveis de comodidade constituem-se em uma ponte para o sedentarismo, o pensamento de que em classes sociais mais elevadas os problemas em relação à saúde estariam resolvidos perde sustentabilidade.

É claro que o patamar material mínimo e universal para se falar em qualidade de vida diz respeito à satisfação das necessidades mais elementares da vida humana: alimentação, acesso à água potável, habitação, trabalho, educação e saúde. No entanto, o lazer e, principalmente, a atividade física de lazer, constituem-se em uma condição básica para a saúde. Primeiro pela condição física 
explorada acima e depois pela condição emocional envolvida neste contexto. Pois, de acordo com Norbert Elias e Eric Dunning, ao tratarem da relação do lazer com certas necessidades sociais:

Na nossa sociedade, como em muitas outras, faz-se sentir uma necessidade corrente de
motivação de fortes emoções que aparecem e, se encontram satisfação, desaparecem, para
só voltarem a manifestar-se algum tempo depois. Seja qual for a relação que esta
necessidade possa ter com outras necessidades mais elementares como a fome, a sede e o
sexo - todos os dados acentuam o fato de que esta representa um fenômeno muito mais
complexo, um fenômeno muito menos puramente biológico -, pode bem considerar-se que
o desprezo quanto à atenção dedicada a esta necessidade constitui uma das maiores lacunas
na abordagem dos problemas da saúde mental (ELIAS; DUNNING, 1992, p. 136-137).

As atividades de lazer, de uma maneira simples ou complexa, a um nível baixo ou a nível elevado, proporcionam ao homem, ainda que por um breve tempo, "[...] a erupção de sentimentos agradáveis fortes que, com freqüência, estão ausentes nas suas rotinas habituais da vida" (ELIAS; Dunning, 1992, p. 137).

A função do lazer, por conseguinte, não é simplesmente, como muitas vezes se pensa, "uma libertação das tensões, mas a renovação dessa medida de tensão, que é um ingrediente essencial da saúde mental" (ELIAS; DUNNING, 1992, p. 137). Por essa razão é que Elias e Dunning fazem menção sobre a complexidade do estudo do lazer, fenômeno em que não estão dissociados fatores ligados ao nível social e os que se encontram nos níveis psicológico e fisiológico.

Com base neste contexto torna-se factível a interpretação de que a maioria das sociedades humanas desenvolve algumas contramedidas em oposição às tensões do stress que elas próprias criam. As sociedades, ao atingirem um nível relativamente avançado de civilização - com relativa estabilidade e com forte necessidade de sublimação - vêem as restrições harmoniosas e moderadas abrangerem toda uma multiplicidade de atividades. As atividades de lazer vão, dessa forma, ter a função, não apenas de libertação das tensões derivadas das pressões sociais rotineiras, mas de sua renovação.

O problema, mais uma vez, recai sobre as crianças hodiernas. Os adultos, mais cedo ou mais tarde, se dão conta do sentimento de "necessidade" frente à falta de atividades físicas e de lazer que lhe proporcionem renovação física e emocional, e têm a opção de ir à busca de algo que lhes satisfaça essa necessidade. Um exemplo dessa busca por atividades que satisfaçam necessidades geradas pela vida complexa, civilizada e urbana nas sociedades modernas é o surgimento das atividades físicas de aventura na natureza (CANTORANI, 2006), atividades que proporcionam alto grau de excitação emocional e contato com atividades que exigem destreza física.

Não obstante, se o olhar é estendido para a realidade do ritmo e estilo de vida das crianças e adolescentes a preocupação é aumentada. É fato que a cultura do lazer entre esta população vem sofrendo alterações. O lazer entre as crianças e adolescentes é cada vez mais mediado pela tecnologia; os espaços - físicos e de tempo - para muitas das brincadeiras que eram comuns entre as crianças são cada vez mais reduzidos. E também é fato que um número crescente de crianças vem sendo acometido de doenças, que até a pouco tempo, espantava o seu crescimento entre os adultos.

A Revista ISTO É, de março de 2006, sob o título: “A explosão da obesidade infantil”, apresentou o alerta trazido pelo relatório divulgado pela International Obesity Task Force (IOTF), uma força tarefa montada por especialistas de diversas nações para estudar meios de combater a obesidade. A entidade informa que o número de crianças obesas no mundo, na época em torno de 155 milhões, se expandirá de modo dramático até 2010. De acordo com a entidade, a porcentagem de jovens com excesso de peso irá praticamente dobrar em quatro anos.

De acordo com o endocrinologista Alfredo Halpern, de São Paulo, "isso significa uma geração condenada a ter problemas cardiovasculares e diabete". Segundo seu depoimento, "é comum crianças de sete anos, obesas, terem essas doenças" (ISTOÉ, 2006).

Evidente que a obesidade não acomete apenas crianças de classes mais elevadas, contudo, há subsídios para se pensar em uma pré-disposição bastante acentuada devido o ritmo de vida de grande parte das crianças que aí se encontram. 


\section{A cultura do lazer e a qualidade do vivido}

Na perspectiva da relação - apontada acima - entre cultura e lazer, é factível a interpretação de que a cultura mais geral de uma sociedade vai atuar na preferência por esta ou aquela forma de lazer; pois, como traço específico da cultura, o lazer está sujeito às relações, significados e especificidades da cultura mais geral e do modo de vida das sociedades.

O lazer é um campo de estudo bastante complexo. E, em parte isso se deve aos vários conceitos que a ele se fundem, ou, que com ele se confundem; ou, talvez numa perspectiva um pouco melhor, e, não menos complexa, que o fundamentam, como ludicidade, recreação, ocupação de tempo livre, de tempo ocioso, de tempo disponível, de prazer, de satisfação.

A satisfação, nesse sentido, é um importante instrumento para o estudo do lazer, ou, como no caso de muitos estudos, do tempo livre. A percepção do indivíduo em relação aquilo de que se ocupa em seu tempo livre, no sentido de entender o que mais o satisfaz, traduz-se em um importante conhecimento para o pretendido entendimento a cerca das ocupações de tempo livre. É fato também que a clareza quanto ao autocondicionamento e o heterocondicionamento deve se fazer presente para uma análise qualitativa a este respeito.

Fruto da aproximação do lazer com a Educação Física, todos esses conceitos vem sendo postos em análise no intuito de entender o lazer. Não apenas o significado do lazer, mas o significado do lazer para aqueles que o praticam e também o entendimento do praticante das atividades em si a respeito de serem ou não lazer são buscas que vem ocorrendo na área em questão. Também dessa aproximação surge o interesse na verificação e discussão de quão sadias são as ocupações de tempo ocioso.

Partindo-se, por conseguinte, da interpretação de que as diferentes experiências de lazer resultam na qualidade da experiência cultural vivida, isso nos remete ao entendimento de que o lazer, ou melhor, as formas de lazer e de experienciar o lazer são bastante significativas para a formação e estruturação da cultura do lazer, e, conseqüentemente, para a qualidade dessa cultura no que se refere a estilos de vida mais próximos ou mais distantes de padrões saudáveis. Neste escopo está também o fato de que a experiência do vivido e não apenas a contemplação do não vivido tem significado direto nesse processo.

E neste ponto cabe novamente ressaltar as inquietações postas no início, ou seja, as que dizem respeito às transformações culturais que (re) significam a apropriação de formas de lazer e de satisfação no lazer das crianças na sociedade em curso; a cultura hodierna do lazer entre as crianças e o seu significado.

Gilberto Freyre enriquece com bastante propriedade o exposto acima, pois, de acordo com os seus escritos, povos menos adiantados no que se refere à modernidade, e que mantém suas raízes, suas culturas, têm muito que ensinar aos que,

\footnotetext{
[...] tendo a eles se adiantado em aspectos tecnológicos da civilização [...] perderam quase de todo a capacidade de viverem ludicamente o tempo livre. Parte em que - repita-se podem receber lições dos tecnologicamente retardados povos ibéricos [...] por isto mesmo, senhores de vastas reservas de cultura folclórica, dentro da qual se conservam danças, músicas, jogos, saudáveis tanto do ponto de vista sociológico como do ponto de vista médico; e capazes de serem adaptadas a situações modernas, em correspondência com a crescente necessidade que experimentam as sociedades civilizadas, de matéria lúdica, festiva, recreativa, com que encham o seu crescente tempo livre [...] em vez de nos entristecermos em sociedades de apenas passivos espectadores de grandes jogos de futebol. Jogos para multidões imensas, porém inermes; de torneios de volibol; de corridas de automóvel (FREYRE, 1973, p. 115).
}

As palavras de Freyre sintetizam de forma bastante rica esse lado negativo do avanço tecnológico e da modernidade. E permite a analogia sobre a realidade a qual vem sendo dedicadas essas linhas, a realidade na qual as crianças estão inseridas; e sobre o entendimento de que talvez "o 
lazer do pobre não seja o mais pobre e o lazer do rico não seja o mais rico".

Nesse processo em curso é preciso, contudo, refletir também sobre outra dimensão do problema. É preciso pensar na motivação social a influenciar os estilos de vida e as apropriações e transformações da cultura do lazer.

Nesse sentido, parece bastante profícuo o encaminhamento dos estudos com foco no heterocondicionamento. Pois, tecnologia, modernidade, conforto e consumo disto tudo são extremamente condicionantes. Vale lembrar que as mídias são veiculadores impiedosos de todos esses condicionantes.

Conforme descreve Gitlin (2003, p. 17), "sem dúvida as mídias têm seu efeito sobre comportamentos e idéias, não tanto porque cada exposição isolada seja poderosa, mas porque se repetem. E se repetem. E se repetem".

Essa é a realidade sócio-cultural moderna. De um modo geral, quando não se está ocupado com responsabilidades de trabalho e/ou estudo se está na torrente da mídia. E essa é uma cultura popular que se globaliza, e, que, de certa forma, pode-se dizer alienante.

É em função dessa alienação que Guy Debord se manifesta com relativo protesto em sua obra "A Sociedade do Espetáculo". Para Debord (1997, p. 13), "toda a vida das sociedades nas quais reinam as modernas condições de produção se apresenta como uma imensa acumulação de espetáculos". Que, em seu entendimento, "tudo o que era vivido diretamente tornou-se uma representação". De acordo com Debord, "o espetáculo em geral, como inversão concreta da vida, é o movimento autônomo do não-vivo". Esse tipo de situação é algo que também se poderia chamar em analogia àquela situação expressa por Sennet (2003, p. 273), ao lembrar a poesia Baudelaire - o "andar para trás" de um corpo em movimento - cada vez mais veloz e passivo - na sociedade moderna.

Para Debord, essa alienação é recíproca e é a essência e a base da sociedade existente:

A alienação do espectador em favor do objeto contemplado (o que resulta de sua própria atividade inconsciente) se expressa assim: quanto mais ele contempla, menos vive; quanto mais aceita reconhecer-se nas imagens dominantes da necessidade, menos compreende sua própria existência e seu próprio desejo. Em relação ao homem que age, a exterioridade do espetáculo aparece no fato de seus próprios gestos já não serem seus, mas de um outro que os representa por ele. É por isso que o espectador não se sente em casa em lugar algum, pois o espetáculo está em toda parte (DEBORD, 1997, p. 24).

O espetáculo na sociedade, assim como as mídias, corresponde a uma fabricação concreta da alienação, é o âmago do irrealismo da sociedade real. Sob todas as suas formas particulares informação, publicidade, propaganda, etc. - o espetáculo, enquanto produto da mídia, constitui o modelo atual do modo de vida dominante nas sociedades modernas. Dessa forma, este é um aspecto que atua na forma de afirmação onipresente da escolha, e do consumo que decorre dessa escolha.

Minimizar essa alienação de massa é outro ponto que gera inquietação. É preciso atenção sobre os problemas dessa cultura de lazer que se fundamenta no eletrônico, no midiático e no inativo do ponto de vista físico-motor. E aqui manifesta-se a necessidade da orientação a respeito dos benefícios e malefícios pertinentes a este ou aquele estilo de vida.

Assim, parece legítimo ressaltar a importância da adoção de uma postura diretiva no que diz respeito tanto ao estudo quanto à quaisquer tentativas de mudança deste quadro. Como bem diz Snyders (2001, p. 285) "nada é pior do que a perversão do que há de melhor".

De acordo com Snyders (2001, p. 285), "na base da não-diretividade, as exigências são as melhores; mas, quando essas exigências passaram pela não-diretividade, quando se tornaram pedagogia não-diretiva, receamos terem sido literalmente corrompida". Para este autor, a nossa época é marcada pela necessidade de uma renovação que não se furte a uma nova análise da sociedade.

E, para esta análise, talvez o caminho seja o apontado por Pulo Freire quando escreve que para ensinar é preciso o reconhecimento de ser condicionado: "gosto de ser gente porque, 
inacabado, sei que sou um ser condicionado mas, consciente do inacabamento, sei que posso ir mais além dele" (FREIRE, p. 59).

\section{Considerações finais}

O debate a respeito das condições de vida e da qualidade de vida das crianças, e a sua relativização às formas de lazer presentes em suas vidas é algo necessário. O objetivo deste estudo é elucidar a necessidade de aprofundamento do estudo do significado das formas de lazer frente a um processo de desenvolvimento social, urbano e tecnológico que direciona a humanidade a um estado cada vez mais envolto em conforto e comodidade. E, frente a esta perspectiva, analisar o tipo de vida a que as crianças envolvidas neste contexto vêm sendo submetidas. Estas são bases para se pensar os problemas que provavelmente surgirão dessa realidade, e possíveis alternativas para este processo.

Para isso, é buscado o aprofundamento dos estudos sobre a ligação entre os modos de vida e as atividades físicas de lazer; sobre a ligação entre a mobilidade social e a qualidade de vida; e sobre a ligação entre a mobilidade social e a apropriação de culturas de lazer.

Partiu-se, por conseguinte, da interpretação de que as diferentes experiências de lazer resultam na qualidade da experiência cultural vivida; e, diante de tal interpretação, apresentou-se como factível o entendimento de que as formas de lazer, de experienciar o lazer são significativas para a formação e estruturação da cultura do lazer.

Conseqüentemente, firma-se também o entendimento de que a qualidade dessa cultura de lazer pode interferir objetivamente na estruturação de modos de vida mais próximos ou mais distantes de padrões saudáveis.

Também é destacado o fato de que a experiência do vivido e não apenas a contemplação do não vivido tem significado direto nesse processo. A satisfação, nesse sentido - ponto ainda a ser aprofundado -, é um aspecto importante para acompanhar toda a relação entre lazer e condição de vida exposta neste trabalho, e, sobretudo, as apropriações e transformações da cultura do lazer.

\section{Referências}

A explosão da obesidade infantil. ISTO É Online, São Paulo, mar. 2006. Seção Medicina \& BemEstar. Disponível em: <http://www.terra.com.br/istoe/1899/medicina/1899_exploracao_da_obesidade_infantil.htm>. Acesso em: 25 jun. 2006.

BERGER, P.; LUCKMANn, T. A Construção Social da Realidade. 3. ed. Petrópolis: Vozes, 1976. Tradução: Floriano de Souza Fernandes.

BRACHT, V. Educação Física Escolar e Lazer. In: Werneck, C. L. G. Lazer, Recreação e Educação Física. Belo Horizonte: Autêntica, 2003, p. 147-173.

CANTORANI, J. R. H. Indivíduos em busca de excitação e prazer: análise sociológica da expansão as atividades físicas de aventura na natureza. Ponta Grossa, 2006. Originalmente apresentada como dissertação de mestrado, Universidade Estadual de Ponta Grossa, 2006.

DEBORD, G. A sociedade do espetáculo. Tradução Estela dos Santos Abreu. Rio de Janeiro: Contraponto, 1997.

ELIAS, N. Introdução à sociologia. Tradução Maria Luiza Ribeiro Ferreira. Lisboa: Edições 70, 1980. 
ELIAS, N., DUNNING, E. A Busca da Excitação. Tradução Maria Manuela Almeida e Silva. Lisboa: DIFEL, 1992.

FREIRE, P. Pedagogia da Autonomia: saberes necessários à prática educativa. São Paulo: Paz e Terra, 1996.

FREYRE,G. Além do Apenas Moderno: sugestões em torno de possíveis futuros do homem, em geral, e do homem brasileiro, em particular. Rio de Janeiro: José Olympio, 1973.

GITLIN, T. Mídias sem limite: como a torrente de imagens e sons domina nossa vida. Tradução Maria Beatriz de Medina. Rio de Janeiro: Civilização Brasileira, 2003.

HELLER, A; FEHÉR, F. A condição política pós-moderna. Tradução Marcos Santarrita. Rio de Janeiro: Civilização Brasileira, 1998.

MINAYO, M. C. de S.; HARTZ, Z. M. de A.; BUSS, P. M. Qualidade de vida e saúde: um debate necessário. Ciência \& Saúde Coletiva, 5 (1): 7-18, 2000. disponível em: $<$ http://www.scielo.br/scielo.php?script=sci_arttext\&pid=S1413-81232000000100002>. Acesso em: 07 set. 2006, 16:30:00.

SNYDERS, G. Para onde vão as pedagogias não-diretivas? Lisboa: Moraes Editores, 1978. 